\title{
O PROBLEMA DA JUDICIALIZAÇÃO DA SAÚDE NO BRASIL: SUGESTÃO DE NOVOS RUMOS
}

\author{
Josué Mastrodi ${ }^{1}$ \\ Elaine Cristina de Souza Ferreira Fulfule ${ }^{2}$
}

\section{Resumo}

O ponto fundamental desenvolvido neste trabalho gira em torno da quantidade de intervenções judiciais na ação discricionária dos Administradores de políticas de saúde, bem como da legitimidade dessas intervenções. Temos por finalidade aqui, contribuir para a discussão acerca da judicialização do direito à saúde no Brasil. Neste trabalho, procedemos a revisão da jurisprudência do Supremo Tribunal Federal e da legislação federal mais atual, bem como a revisão de pesquisas relacionadas a este mesmo tema. Verificamos que, embora o STF entenda a prestação do direito à saúde como de responsabilidade concorrente dos entes federativos, impondo ao Administrador de qualquer ente federativo o dever de prestar serviços de saúde, parece não considerar que tal postura acarreta graves problemas na execução orçamentária. Além disso, talvez pela falta de iniciativa do legislador, mas principalmente pelo ativismo judicial, há incontáveis pedidos judiciais de tutela individual ao bem da saúde. A doutrina reflete a este respeito, procurando alternativas viáveis para a administração orçamentária e a promoção do direito à saúde. Defendemos a releitura da questão da intervenção do Judiciário, sugerindo a criação de espaços de diálogos institucionais, de modo que o Estado estabeleça, por seus três Poderes, o agir sobre a prestação do direito à saúde.

Palavras-Chave: Judicialização da saúde. Ativismo judicial. Direito à saúde. Políticas públicas. Diálogos institucionais.

\section{INTRODUÇÃO}

A Constituição brasileira promulgada em 1988 trouxe ao Direito nacional algumas premissas políticas novas até então. Se, por um lado, foi considerada a Constituição Cidadã, por trazer em seu bojo os direitos e garantias fundamentais, ampliando a abrangência destes de forma a incorporar os direitos sociais (denominados direitos de segunda dimensão), conforme verificado nos artigos $5^{\circ}$ e $6^{\circ}$, e ainda os declarando de eficácia imediata (art. $\left.5^{\circ}, \$ 1^{\circ}\right)$, por outro lado também positivou os mesmos direitos sociais nesta carta, dando-lhes eficácia contida e caráter de norma programática, como podemos constatar no artigo 196, quando o legislador diz que "a saúde é direito de todos e dever do Estado, garantido mediante políticas sociais e econômicas que visem à redução do

\footnotetext{
${ }^{1}$ Doutor em Filosofia e Teoria Geral do Direito pela USP. Professor da Faculdade de Direito da PUC-Campinas. E-mail: mastrodi@puc-campinas.edu.br

${ }^{2}$ Especialista em Saúde Pública pela Unaerp. Graduanda em Direito pela PUC-Campinas. E-mail: elainefulfule@gmail.com
} 
risco de doença e de outros agravos...". Sobre o direito à saúde, os artigos 196 a 200 tratam do assunto como "direito de todos e dever do Estado", remetendo este mesmo Estado a uma série de obrigações de prestação social, a serem posteriormente regulamentadas pela Lei Federal n. 8080/1990.

Enquanto estas regulamentações não ocorriam, o Judiciário viu-se inundado por ações individuais que visavam a garantir a prestação do direito à saúde pois, como veremos a seguir, os operadores do direito têm interpretado o direito à saúde como direito fundamental de eficácia imediata -algo que acabou sendo confirmado por decisões do Supremo Tribunal Federal (STF), ainda que em sede de decisões interlocutórias, muito embora, ao menos em nossa opinião, trata-se de direito social de eficácia limitada ou mais, de eficácia contida, pois dependente de políticas públicas e de conteúdo altamente discricionário por parte da Administração. Este debate tem se estendido até hoje, tanto na seara jurisprudencial quanto na doutrinária.

Se, por um lado, os cidadãos têm direito de buscar a tutela de seus direitos, e o Judiciário declara que o direito à saúde deve ter um tratamento diferente do quanto previsto pelo Administrador (mais profundo, mais completo, imediato, independentemente de sua previsão em políticas públicas), por outro, a declaração de eficácia imediata desse direito impede - ou ao menos inviabiliza - o planejamento do Administrador quanto à otimização dos recursos (materiais, humanos, orçamentários) à disposição para promover políticas de saúde. Em tese, o uso de recursos finitos para promover um tratamento individual determinado por ordem judicial compromete o planejamento de políticas visando à promoção coletiva do direito à saúde.

Neste artigo, apresentaremos de maneira breve alguns exemplos deste problema, a fim de embasar o debate acerca do papel do Judiciário (em especial do STF) no que se convencionou chamar de judicialização da Saúde, pois entendemos não haver a alegada "invasão de Poderes", ao menos no que concerne à ação do Judiciário sobre as competências discricionárias do Executivo.

Em que pese afirmar-se uma alegada "invasão de poderes" do Judiciário sobre competências exclusivas e discricionárias do Executivo, entendemos que não há propriamente invasão (algo que também já foi desenvolvido por Dantas e al, 2013, p.67-74). Direitos devem ser protegidos judicialmente e levados em conta pela Administração, de modo que novas políticas contemplem os direitos afirmados pelo Judiciário. Em decorrência disto, há que se discutir sobre a necessidade de administrar a sobrecarga de demandas que buscam a tutela judicial do direito à saúde, em seus mais variados aspectos.

O Judiciário não está suplantando o Administrador ao decidir prioridades em casos concretos sob seu julgamento. Por outro lado, o Administrador não faz nada de errado ao, discricionariamente, utilizar de seu arcabouço técnico para definir as medidas que considera as mais eficientes e adequadas para a promoção efetiva do direito à saúde de forma coletiva, na medida de seus recursos e conforme as urgências e prioridades definidas ora pela legislação, ora por seu próprio entendimento, cuja prerrogativa, de natureza exclusiva da Administração, 
não deve ser substituída por qualquer outro poder do Estado.

As decisões singulares havidas em processos judiciais, portanto, não deveriam ter o condão de determinar mudanças nas políticas públicas decididas pelo Administrador, a menos que fossem consideradas ilícitas. Por outro lado, é justa a crítica de que as demandas individuais permitem a seus autores que recebam recursos da área de saúde de modo prioritário em relação aos demais cidadãos que, por um ou outro motivo, se submeteram aos critérios de atendimento da própria Administração.

Visto deste ângulo, cria-se um impasse nas relações institucionais, lastreada no entendimento de que a intervenção judicial impõe ações da Administração que, de outra forma, não seriam executadas. Por óbvio, a construção de uma via de diálogo institucional, a fim de equacionar as dificuldades geradas na execução orçamentária, seria altamente recomendável,

Nesta vertente, defendemos a existência de espaços que incluam o debate popular (que, todavia, não se confundem com audiências públicas, visto ser esta composta para discutir um assunto pontual por tempo limitado) a fim de legitimar as ações discricionárias da Administração. O que torna esta perspectiva positiva é a intensificação do sistema de freios e contrapesos, trazendo o Judiciário (por meio de suas entidades representativas, tais como o CNJ, por exemplo) ao debate franco com as instâncias legislativas e administrativas, e propiciando decisões consensuais e mais exequíveis do ponto de vista prático, de forma a buscar o equilíbrio entre a garantia da tutela individual e a necessidade da adequação das contas públicas na prestação de saúde de modo coletivo.

Outras formas de equacionamento derivariam de jurisprudência ou de alterações legislativas, muito mais onerosas e demoradas do que a geração deste espaço de discussão, que poderia ser iniciado por qualquer das partes, embora, por óbvio, seja de interesse, a priori, da Administração, haja vista sua competência originária e exclusiva para promover as políticas de saúde e a destinatária das decisões judiciais em questão.

Um fato complicador, porém, em qualquer diálogo institucional, é a indisponibilidade do interesse público, que em tese não permite transação. Alterações legislativas buscam flexibilizar este dogma jurídico (sendo os mais expressivos, sem dúvida, o advento da Lei 13.105/2015, que se convencionou chamar de "novo" Código de Processo Civil e que traz para o bojo dos atos processuais a possibilidade de conciliação e mediação, e da Lei 13.140/2015, que prevê em seus artigos 32 e seguintes a autocomposição de conflitos pelos órgãos e entidades da Administração Pública, porém sem margem para composições fora da Administração Pública ou que envolvam direitos de natureza extrapatrimonial), mas ainda há resistências. Orçamento público e direitos fundamentais precisam ser compreendidos de modo tal que aquele seja capaz de comportar demandas individuais e promoção coletiva de políticas de saúde.

Neste trabalho, buscamos pontuar a necessidade de um novo processo de discussão institucional, 
visando ao equacionamento das diversas interpretações acerca desse interesse público indisponível, que precisa ser atingido seja pelo Legislador, seja pelo Juiz, seja pelo Administrador.

\section{O IMPASSE DOUTRINÁRIO}

Muito se tem dito, nos últimos tempos, acerca da questão da judicialização da saúde: uns contra, outros a favor, mas todos convergindo para o mesmo ponto: trata-se de um dado de realidade, um fato que se expressa no dia a dia dos fóruns. O Administrador Público da saúde invariavelmente tem sofrido interferência, em sua atribuição constitucional, de órgãos do Poder Judiciário, em geral determinando a modificação de decisões discricionárias sobre a forma como organiza a prestação do direito à saúde no Brasil.

Dallari (2009) assinala que tanto a noção de Direito quanto a noção de Saúde sofreram transformações a partir do conceito de Estado de Bem-Estar Social do século XIX, incluindo situações complexas pelas quais a construção do direito à saúde passaria pela percepção do ambiente em que este mesmo direito se insere. Essa autora destaca que essa percepção do ambiente se dá pela participação direta do legislador, bem como dos próprios cidadãos envolvidos neste processo.

Além disso, Sarlet (2012) destaca que a Constituição de 1988 trouxe a questão do debate democrático em seu âmago. Quando de sua promulgação, deu-se a assunção de sua centralidade normativa afirmando as garantias e direitos fundamentais com centralidade absoluta no Direito brasileiro. O Preâmbulo da Constituição já exibe o forte compromisso com a questão da justiça social, o que culmina na positivação dos direitos fundamentais como alicerce deste compromisso. Além disso, o artigo $3^{\circ}$ da Constituição Federal prescreve, dentro os objetivos da República, em seus incisos I e III, a construção de uma sociedade justa e a redução das desigualdades sociais.

Apesar de a Constituição brasileira ser principiológica, contendo conceitos indeterminados que demandam interpretação, esses mesmos conceitos conferem certa sensação de segurança aos cidadãos, já que promovem a proteção destes pela positivação de direitos fundamentais.

Somada essa sensação de segurança à própria centralidade constitucional no Direito, mais e mais cidadãos se veem, pois, autorizados a buscar a garantia de seus direitos de prestação estatal em matéria de direitos fundamentais, nomeadamente a saúde, junto ao Poder Judiciário. Até porque, vale lembrar, que a própria Constituição Federal incentiva o cidadão a procurar por este Poder, pois, conforme podemos verificar no inciso XXXV do artigo 5o, "a lei não excluirá da apreciação do Poder Judiciário lesão ou ameaça de lesão a direito".

Por outro lado, a possibilidade de concessão da prestação de saúde pela Administração não é ilimitada, embora seja comum que se entenda qualquer negativa em sua concessão como ato inconstitucional, justamente em função da positivação do direito à saúde como direito social fundamental. Somadas todas essas alegações, que 
impulsionam os cidadãos a procurarem a tutela judicial dos seus direitos, percebemos que a pressão gerada no Poder Judiciário pela demanda excessiva de processos que tramitam com o mesmo objeto jurídico (que, por se tratar de direito à saúde, assume viés de urgência), acaba por ser tão expressiva que se impõe a tentativa de aliviar a carga de trabalho das varas e, ao mesmo tempo, garantir os direitos fundamentais das partes envolvidas.

Assim, a discussão das garantias fundamentais e da interpretação do texto constitucional a fim de que se dê implementação a estes mesmos direitos e garantias, pode e deve ser feita também pela via jurisdicional, que não deve se furtar a dar resposta a estas demandas. O Judiciário ainda assume, até este momento, o polêmico protagonismo na garantia do direito fundamental à saúde, tendo que sopesar o entendimento da população de que seu direito é ilimitado (o que evidentemente não é verdade, pois isto seria o mesmo que acreditar que os recursos financeiros e humanos são ilimitados), contra o entendimento da Administração Pública, que alega que se deve dar guarida apenas a questóes inerentes a demandas coletivas, estabelecidas tanto do ponto de vista técnico-estatístico como a partir da discricionariedade política para estabelecimento de ações e serviços públicos (até porque, os recursos disponíveis para promoção das políticas públicas de saúde são limitados).

Portanto, em que pese a ideia originária do legislador de conceder uma faceta democrática ao processo de reinvindicação dos direitos fundamentais, notadamente o direito à saúde (o que sem dúvida alguma é de indiscutível importância), o que vislumbramos neste momento é um entendimento inadequado desta intenção, na medida em que particulariza, de maneira crescente, o que deveria ser coletivo.

Não que as necessidades particulares não devam ser tuteladas (é claro que devem, caso contrário não haveria Estado Democrático de Direito, posto que este se embasa no princípio da legalidade), porém há que se ter um mecanismo que alinhave o Legislador, o Juiz e o Administrador num processo em que as prestações se tornem eficientes e ao mesmo tempo uniformes e igualitárias, garantindo assim o igual acesso à prestação positiva de saúde a todos os cidadãos, e não apenas àqueles que possuam recursos financeiros ou intelectuais para reivindicar seus direitos junto ao Judiciário.

\section{A BUSCA PELA PACIFICAÇÃO JURISPRUDENCIAL E LEGISLATIVA}

Em termos legislativos, a Lei 8.080/1990 trouxe uma contribuição eficiente ao desenvolvimento do sistema público de saúde ao estabelecer e regulamentar as diretrizes do Sistema Único de Saúde (SUS). Porém, algumas de suas assertivas, por serem por demais genéricas, terminaram por dar azo a interpretações, acolhidas por muitos magistrados, de que são atribuições do SUS a "assistência terapêutica integral, inclusive farmacêutica" constante no artigo $6^{\circ}$, inciso I, alínea $\mathrm{d}$, que, em conjunto com o disposto no artigo 7º, que versa sobre a "integralidade" da assistência à saúde em seu inciso II, "entendida como conjunto articulado e contínuo das ações e serviços preventivos e curativos, individuais e coletivos, exigidos para cada caso em todos os níveis de 
complexidade do sistema”, interpretações essas que permitiriam considerar que, por serem diretrizes legislativas e executivas positivadas são, por isso mesmo, judicialmente exigíveis.

A Lei n. 12.401, trazida à luz onze anos depois, em 28 de abril de 2011, tenta regulamentar de maneira mais clara os artigos 19-M a 19-U da Lei n. 8.080. Esta lei adiciona a ideia de controle sobre a aplicação de novas tecnologias ao SUS, por meio da Comissão Nacional de Incorporação de Tecnologias (CONITEC), que tem por atribuições "a incorporação, exclusão ou alteração de novos medicamentos, produtos e procedimentos, bem como a constituição ou alteração de protocolo clínico ou de diretriz terapêutica", e foi posteriormente regulamentada pelo Decreto n. 7.646, de 21 de dezembro de 2011, decreto este que define como diretrizes da referida Comissão, dentre outras, o disposto em seu artigo $3^{\circ}$, I, a "universalidade e a integralidade das ações de saúde no âmbito do SUS, com base no melhor conhecimento técnico-científico disponível...”.

A CONITEC é uma comissão que inclui, exclui ou não permite exclusão de determinadas tecnologias ao SUS, sempre apontando suas decisões em relatórios motivados. Em 2014, por exemplo, publicou 31 relatórios relacionados ao direito à saúde e sua promoção por meio do SUS. A CONITEC foi criada não só para incorporar novas tecnologias ao SUS, mas também para promover a difusão dos estudos sobre as tecnologias em saúde. (SILVA et al, 2012). Além disso, é incumbência da CONITEC fomentar estudos na área da saúde e a promoção ao desenvolvimento institucional, dentre outras atribuições. Sua composição é colegiada, contando com a participação de diversas esferas da Administração Federal direta e indireta. Silva et al (2012) destacam que, no campo específico da avaliação das tecnologias de saúde, a padronização dos métodos carecia de confiabilidade e que, em 2012, apenas quatro publicações na área tentavam padronizar estes dados.

A complexidade dos relatórios e a discricionariedade de suas decisões técnicas trazem à CONITEC um viés de responsabilização por aquilo que o Executivo aponta como passível de concessão técnica, frente a um pedido de prestação positiva da saúde. Apesar das dificuldades, a assistência farmacêutica do SUS assistiu, nos últimos anos, a um realinhamento de políticas farmacêuticas, decorrentes de várias normatizações, dentre estas a que o usuário receba a prescrição do SUS, segundo a Relação Nacional de Medicamentos Essenciais (RENAME) e dos Protocolos Clínicos e Diretrizes Terapêuticas (PCDT), sendo a dispensação realizada apenas em unidades do SUS. (SANTOS-PINTO et al, 2013). Estas autoras destacam que a RENAME, que era composta por cerca de 350 medicamentos de aceitação mundial e de uso baseado em evidências foi transformada, após a portaria MS nº 533 de 28 de março de 2012, numa lista única de mais de 810 medicamentos "essenciais", muitos deles não baseados em evidências, o que torna a normatização fácil ponto de tensão entre os diversos interesses que pugnam incessantemente pela incorporação de novas tecnologias como sendo "essenciais".

Tendo em vista o fato de esta adição ter sido feita sem o desejável balizamento das evidências, e sim de forma "acrítica", por conta das pressões judiciais geradas a partir de demandas individuais (que não 
necessariamente cumprem diretrizes técnicas), as autoras consideram que as expectativas geradas com relação à ação reguladora da CONITEC não são atingidas. Demonstram também que a CONITEC não foi capaz de acompanhar, no que tange ao contexto técnico-científico, a alta "velocidade" com que estas solicitações de incorporações de insumos relativos à saúde são trazidas à sua avaliação. E, ao final, concluem:

A adoção de um amálgama das inúmeras listas de financiamento público, que nasceram e prosperaram nos últimos anos, como 'RENAME', representa um retrocesso, fortalecendo a lógica da oferta financiada como substitutivo à lógica da necessidade calcada em prioridades. A integralidade segue sendo uma noção útil e ética para identificar valores e características desejáveis para o sistema... (SANTOS-PINTO et al, 2013, p.1057)

Assim sendo, constata-se que o legislador, por meio da Lei 12.401/2011, tentou suprir a carência legislativa acerca dos meios de incorporação de tecnologias na Saúde, favorecendo o Executivo, no sentido de criar dispositivo legal que permita a atualização das tecnologias. No entanto, estas se desenvolvem de maneira muito mais veloz do que a burocracia estatal pode acompanhar, e as iniciativas legislativas para que o SUS conseguisse suprir todas as necessidades não têm logrado êxito.

Este movimento do Poder Público não foi de todo suficiente nem para explicitar os limites da Administração, nem para esclarecer as atribuições de cada nível federativo, eventualmente retirando do Poder Judiciário a tarefa de decidir sobre a concessão dos alegados direitos às prestações de saúde. Agravando a situação técnico-política que recai sobre o Judiciário, verificam-se solicitações realizadas sem os subsídios técnicos necessários ao convencimento do magistrado acerca da procedência do direito requerido. Essa insuficiência de subsídios técnicos decorre, como veremos a seguir, da incapacidade do próprio Poder Executivo em documentar, de maneira inequívoca, a lesão à ordem pública, que embasa suas justificativas no sentido de explicar o porquê da não-dispensação de determinadas medicações, ou do não-acesso a determinadas terapêuticas.

Os problemas prosseguiram, pois regulamentar prestação à saúde é algo extremamente complexo, e envolve uma plêiade de necessidades e interesses. Isto converge, ao fim e ao cabo, para uma série de questionamentos, como por exemplos, o que diz respeito à tese da competência orçamentário-legislativa situar-se em outra esfera, ${ }^{3}$ à crítica a respeito da tênue delimitação do mínimo existencial ${ }^{4} \mathrm{e}$ à análise do comportamento dos profissionais de saúde, nomeadamente dos médicos, por não abrirem mão de suas condutas terapêuticas, gerando impasses de cunho ético. ${ }^{5}$ Estas questões, por impedirem o tratamento buscado pelos cidadãos, têm

\footnotetext{
${ }^{3}$ A questão da competência orçamentária e legislativa na concessão do direito fundamental à saúde recebeu entendimento do STF no sentido de ser de responsabilidade de todos os entes federativos, com efeito de repercussão geral.

${ }^{4}$ A questão do mínimo existencial, não obstante sua importância, não é objeto de discussão neste artigo.

${ }^{5}$ Outra discussão que também não cabe neste artigo, mas que assume importância no contexto geral do problema, uma vez que os profissionais da saúde, notadamente os médicos, têm autonomia para indicar o que acreditam ser a melhor terapêutica para seus pacientes, e isso é não só uma prerrogativa, como, inclusive, uma obrigação. O impasse começa a ser gerado no momento em que, a fim de obter os melhores resultados no tratamento individual, o médico prescreve terapêuticas alternativas, que apesar de já terem bons resultados no exterior, ainda não foram aprovadas pela ANVISA. Vale lembrar que a agência reguladora tem discricionariedade total em sua área de atuação, e que sua atuação deslegaliza o processo de discussão dentro da área de sua
} 
motivado a procura, por estes, de solução a seus problemas junto ao Poder Judiciário, em busca daquilo que o cidadão e seu médico julgam ser o necessário para manutenção de sua vida e dignidade.

Ademais, há também a questão sobre a responsabilidade solidária da União, Estados, Municípios a respeito da prestação social relativa à saúde. A Lei n. 8.080/1990 define, dentre as competências comuns às três esferas, muitas atribuições, porém a maior parte se resume a elaborar políticas de ação, fiscalização e controle sobre os demais órgãos públicos e serviços privados de saúde. Em nenhum lugar do artigo 15 da citada Lei se pode depreender que as competências comuns passam pelo atendimento ao cidadão em casos que não os emergenciais ou decorrentes de situação de calamidade. Apesar disso, o artigo 23, inciso II da Constituição Federal determina ser competência comum de todas as esferas federativas "cuidar da saúde e assistência pública, da proteção e garantia das pessoas portadoras de deficiência”.

Ora, a interpretação desse inciso II, por sua natureza principiológica, leva-nos a supor que todas as esferas federativas têm a atribuição de estabelecer ações de saúde e prestar assistência pública nesta área, sem especificar o sentido da palavra saúde, nem quais seriam essas ações. O único aspecto que diferenciaria União, Estados e Municípios em relação à saúde encontra-se na questão legislativa, prevista pelo artigo 24 da Constituição Federal, inciso XII, que determina a União como editora de normas gerais, e os Estados e Municípios como editores de normas suplementares. Neste sentido, a Lei Complementar n. 141, de 13 de janeiro de 2012, veio estabelecer os valores mínimos a serem destinados a cada esfera federativa para implementar ações e serviços de saúde, explicitando que serão definidos como ações de saúde

Artigo $2^{\circ}$. -aquelas voltadas para a promoção, proteção e recuperação da saúde que atendam, simultaneamente, aos princípios estatuídos no art. 7o da Lei no 8.080, de 19 de setembro de 1990, e às seguintes diretrizes:

I. Sejam destinadas às ações e serviços públicos de saúde de acesso universal, igualitário e gratuito;

II. Estejam em conformidade com objetivos e metas explicitados nos Planos de Saúde de cada ente da Federação; e

III. Sejam de responsabilidade específica do setor da saúde, não se aplicando a despesas relacionadas a outras políticas públicas que atuam sobre determinantes sociais e econômicos, ainda que incidentes sobre as condições de saúde da população.

IV. Parágrafo único. Além de atender aos critérios estabelecidos no caput, as despesas com ações e serviços públicos de saúde realizadas pela União, pelos Estados, pelo Distrito Federal e pelos Municípios deverão ser financiadas com recursos movimentados por meio dos respectivos fundos de saúde.

A referida Lei Complementar ainda versa sobre a contribuição financeira de cada ente federativo para a manutenção das ações em saúde, bem como seus critérios de aplicação, fiscalização e das sanções aplicadas em caso de descumprimento das diretrizes apontadas.

Levando em consideração a centralidade normativa da Constituição em nosso ordenamento jurídico,

competência, ou seja, suas decisões discricionárias, desde que não notadamente viciadas ou desproporcionais, têm plena vigência e aplicação imediata. Assim, teoricamente, o Judiciário não deveria autorizar a concessão de medicação que a ANVISA não aprovou. 
podemos compreender por onde começam as controvérsias quanto à competência em dar resposta às ações individuais ou coletivas para concessão de medicações ou tratamentos específicos.

Há, aparentemente certa dificuldade dos órgãos públicos em justificar a não concessão de determinada medicação ou tratamento aos cidadãos. Alguns pedidos de suspensão de liminar, ${ }^{6}$ suspensão de tutela antecipada ${ }^{7}$ e suspensão de segurança ${ }^{8}$ que transitavam no Supremo Tribunal Federal, conforme exporemos a seguir, alegavam "grave dano à ordem pública" para não conceder o medicamento ou tratamento demandado, sem todavia convencer os Ministros quanto à real existência do dano relatado.

Em comum, União e Estados tendem a se isentar de suas respectivas responsabilidades, alegando, com base em seu entendimento sobre distribuição de competências prevista na Lei n. 8.080/90, que a execução das ações de saúde competiria exclusivamente à esfera municipal, não havendo cabimento sua inclusão nos polos passivos das demandas.

Alegavam, ainda, que os procedimentos e medicações solicitados não faziam parte dos protocolos determinados pelo SUS, e portanto não estariam inseridas nas ações programáticas de saúde do município ou previstas no orçamento dos entes federativos, e que o fornecimento do bem requerido prejudicaria outras ações que visavam a fornecer o "mínimo existencial" à coletividade, posto que a restrita dotação orçamentária impedia a implementação das duas ações simultaneamente, a prevista pelo Administrador ea imposta pelo Judiciário.

Este entendimento, todavia, não convenceu o Supremo Tribunal Federal. Em sua evolução jurisprudencial, nota-se estar pacificado o entendimento de que a saúde é direito fundamental, que sua garantia se inclui no rol de deveres do Estado e que deve ser prestado solidariamente pelos entes da federação.

Contudo, esse posicionamento do Judiciário não encontra ressonância no Legislativo, que entende ter sua seara invadida, ofendendo o princípio da repartição de poderes, nem no Executivo, que entende como afronta à sua prerrogativa primordial, isto é, o exercício de sua discricionariedade, a imposição, por meio de ordens judiciais, de realocação de recursos de forma diferente daquela já definida pelo Administrador para cumprimento de seu dever institucional.

Por este motivo, e tentando identificar os pontos que conduziam às dificuldades, o então Presidente do Supremo Tribunal Federal, Ministro Gilmar Mendes, convocou uma audiência pública em abril de 2009. Nessa oportunidade, concluiu que

impõe-se ao magistrado o desafio de resolver um complexo quebra-cabeça de conciliar a eficácia imediata dos direitos sociais, inclusive considerando seu aspecto evolutivo, a universalidade do sistema e a desigualdade social, o direito subjetivo e o direito coletivo à saúde, a escassez de recursos e o uso indevido do orçamento, a justiça comutativa e a justiça distributiva, dar prioridade às políticas de prevenção ou à recuperação; a efetiva participação

\footnotetext{
${ }^{6}$ Como, por exemplo, o SL 47 AgR/PE, do STF, relatoria do Ministro Gilmar Mendes, 17/03/2010.

${ }^{7}$ Pode-se verificar na STA 175 AgR/CE, STF, relatoria do mesmo Ministro, 17/03/2010.

${ }^{8}$ Também verificado na SS /3989- PI, de 07/04/2010, relatoria do Ministro Gilmar Mendes.
} 
da comunidade no sistema, a distribuição de tarefas entre os entes da federação e as desigualdades regionais (MENDES, 2009, p.9).

O ministro, outrossim, recomendava cautela na avaliação das demandas, pois considerava que não se deveria contemplar a todo e qualquer pedido, posto que a simples concessão do direito, sem levar em conta seu contexto, poderia causar, efetivamente, grave lesão à ordem administrativa e subsequente prejuízo ao SUS. ${ }^{9}$ Além do que, à parte das requisições de prestações de medicações regularmente registradas e comercializadas no país, os tratamentos ditos experimentais não deveriam ser incluídos no rol dos que devem ser obrigatoriamente fornecidos pelo Estado, e sim pela instituição que realiza a pesquisa, enquanto perdurar o benefício ao paciente que dele se utilizar.

Quase um ano depois desta audiência pública, em 17/03/2010, ao julgar o Agravo Regimental da Suspensão de Liminar n. 47, de Pernambuco, Gilmar Mendes profere voto no processo que trouxe nova perspectiva para as questões relativas à judicialização da saúde. Relatou que, no âmbito do Supremo Tribunal Federal, eram crescentes as controvérsias acerca de ordens judiciais que determinavam ao Estado fornecer medicações e tratamentos, e que inclusive era recorrente a tentativa do Poder Público de suspender as decisões judiciais neste sentido.

Contudo, havia notado, na audiência pública de 2009, que as intervenções judiciais não haviam se dado em face de omissão na criação de políticas públicas de saúde, mas sim no sentido de obrigar o cumprimento das políticas já estabelecidas, não havendo que se falar, portanto, de invasão do poder discricionário do Administrador na elaboração das referidas políticas.

Relata, então, que o Poder Judiciário necessitaria avaliar se a não prestação do direito reclamado seria consequência de uma omissão legislativa, de uma escolha discricionária administrativa negativa ou de uma vedação legal ao fornecimento, e - somente nesta última situação - se haveria o problema do não fornecimento de medicações e procedimentos experimentais ou sem registro na Agência Nacional de Vigilância Sanitária (ANVISA). Mesmo assim, há que se avaliarem as exceções, como quando o requerente provar que as alternativas existentes não são suficientes para contemplar o seu caso.

Em posicionamento ainda mais recente, em 18/03/2014, reafirma esta posição do Supremo Tribunal Federal o Ministro Luiz Fux que, na relatoria do RE 717290 AgR/RS, proferiu voto no sentido de considerar que todas as esferas federativas têm que prover o tratamento de paciente com neoplasia maligna de baço. Para fundamentar seu voto, enumerou os seguintes precedentes: ARE 772.150/RJ, Rel. Min. Carmen Lúcia, DJe 17/10/2013, RE 716.777-AgR/RS, Rel. Min. Celso de Mello, Segunda Turma, DJ 16/5/2013, e ARE-AgR 744.223, Rel. Min. Rosa Weber, DJe 11/9/2013.( Precedentes do Supremo Tribunal Federal)

\footnotetext{
${ }^{9}$ O Ministro Gilmar Mendes considera também que a evolução do conhecimento médico é muito mais rápida que os procedimentos administrativos destinados a incorporá-los nas rotinas do sistema de saúde.
} 
O Ministro Luis Roberto Barroso, em 19 de agosto de 2014, por ocasião do julgamento do ARE 801676 AGR/PE relata com clareza:

...o acórdão recorrido se alinha ao entendimento do Supremo Tribunal Federal no sentido de que, apesar do caráter meramente programático atribuído ao art. 196 da Constituição Federal, o Estado não pode se eximir do dever de propiciar os meios necessários ao gozo do direito à saúde dos cidadãos. Nessa linha, veja-se trecho da ementa da decisão monocrática proferida pelo Ministro Celso de Mello, no RE 271.286:- O direito à saúde - além de qualificar-se como direito fundamental que assiste a todas as pessoas representa conseqüência constitucional indissociável do direito à vida. O Poder Público, qualquer que seja a esfera institucional de sua atuação no plano da organização federativa brasileira, não pode mostrar-se indiferente ao problema da saúde da população... (grifos no original)

Ainda mais recente, há o acórdão relatado pelo Ministro Roberto Barroso, em 07 de junho de 2016, por ocasião do julgamento do ARE 926469 AgR/DF em 2016, realizado pela Primeira Turma daquele Tribunal. Relata o ministro

...A jurisprudência do Supremo Tribunal Federal é firme no sentido de que, apesar do caráter meramente programático atribuído ao art. 196 da Constituição Federal, o Estado não pode se eximir do dever de propiciar os meios necessários ao gozo do direito à saúde dos cidadãos. ... O Supremo Tribunal Federal tem se orientado no sentido de ser possível ao Judiciário a determinação de fornecimento de medicamento não incluído na lista padronizada fornecida pelo SUS, desde que reste comprovação de que não haja nela opção de tratamento eficaz para a enfermidade. Precedentes.

Os acórdãos proferidos pelas Turmas ou mesmo pelo Plenário do STF cristalizam-se no sentido de priorizar sempre o direito fundamental à vida e à dignidade da pessoa humana, sendo acompanhados nesse entendimento pela maior parte dos Tribunais Estaduais. O excerto apresentado acima reflete o entendimento da Suprema Corte sobre o tema nos últimos dez anos, e que não sofreu abalos ou tentativas de modificação, a despeito de suas várias conformações ao longo desta última década. Não há, por assim dizer, predomínio do entendimento deste ou daquele ministro, ou desta ou daquela posição político-partidária; há sim uma unanimidade de entendimento com relação à responsabilidade solidária das três esferas da federação no atendimento às demandas de saúde, bem como da indiscutibilidade quanto à necessidade do atendimento da demanda individual do cidadão que a traz de forma devidamente fundamentada.

Apesar de podermos considerar que a jurisprudência do STF encontrava-se pacificada, ${ }^{10}$ verificamos que isso não é suficiente para a cessação das referidas demandas e da discussão doutrinária. Isso ocorre também a despeito dos notórios esforços legislativos, no decorrer dos últimos quatro anos, para distribuir competências entre as diversas esferas federativas e estabelecer diretrizes no atendimento à saúde da população, conforme já assinalado aqui.

Ainda hoje, mantém-se o posicionamento do Supremo Tribunal Federal neste sentido, com 05 acórdãos

\footnotetext{
${ }^{10}$ Sobre o entendimento consolidado do STF nesse sentido, convém indicar que o Ministro Teori Zavascki, em decisão monocrática recente em sede de Recurso Extraordinário, posicionou-se pela exclusão da União do polo passivo de ações que
} vol.10, n. 02, Rio de Janeiro, 2017.pp. 593-614 
exarados neste sentido, apenas durante o primeiro semestre de $2016 .{ }^{11}$

Mas o que podemos dizer no tocante à doutrina?

\section{MAIS ALGUMAS PALAVRAS SOBRE A CONCEPÇÃO DOUTRINÁRIA DO DIREITO A SAÚDE.}

Muitas discussões, reflexões e controvérsias foram e têm sido criadas no âmbito doutrinário, no afã de tentar entender a atração do cidadão pelas resoluções judiciais, na intenção de prover o que considera serem seus direitos. Esses diretos, enquanto garantias fundamentais por serem afetos à saúde, foram objeto de interessante trabalho de Hunt e Khosla (2008) em que os autores destacam que a diretriz da Organização Mundial de Saúde (OMS), no tocante ao acesso às medicações é, dentre outras, de

.. reconhecer que algumas obrigações decorrentes do direito à saúde não estão sujeitas as restrições orçamentárias, nem tampouco à implementação progressiva, ao contrário, impõe deveres exigíveis de imediato... (Hunt e Khosla, 2008, p.103).

Dallari também destaca que, a partir da Constituição de 1988, a prestação social à saúde passou a ser obrigação concorrente de todos os entes federativos, o que resultou numa alta complexidade normativa, que se expressaria na dificuldade da condução do trato relativo ao direito à saúde no Brasil. Porém, defende que o "arcabouço normativo" construído em torno do direito à saúde permite a realização do direito à saúde por todos os operadores do direito.

Deveras, dentro do disposto pela pesquisadora em tela, podemos inequivocamente destacar que o sucesso das políticas públicas depende mais da sua ressonância nas expectativas da sociedade do que nas do Legislador. Efetivamente, a eficácia social destas políticas tem sido questionada, em grande parte, por conta de muitas vezes possuírem um viés muito mais político-partidário que técnico.

Podemos avaliar que há mais de vinte anos se busca uma solução para tornar as políticas de saúde acessíveis a toda a população, mas que, apesar de todos os esforços, elas continuam causando descontentamento. Isso, do nosso ponto de vista, deve-se ao fato de o Legislador e o Administrador verem a saúde como uma via de mão única, quando na verdade seu equacionamento transita para a integralização das ações de saúde com outras que incluem obras de infraestrutura e educação, por exemplo, contando inclusive com alterações do "modus operandi” da própria Administração, que poderia implantar práticas que favorecessem o fluxo das informações e das resoluções, aliviando a sobrecarga do Judiciário que, por si, dificilmente deixará de conceder ordens judiciais

pleiteavam fornecimento de remédios, sob o argumento de que a execução dessa prestação caberia exclusivamente aos Municípios e, supletivamente, aos Estados. RE 780.683/AL, j. 01/08/2014.

${ }^{11}$ Neste sentido: RE 933857 AgR/RN, de 16/02/2016, de relatoria da Ministra Rosa Weber; ARE 936301 AgR/ES, de relatoria do Ministro Edson Fachin, de 15/03/2016, ARE 831915 AgR/RO, de relatoria do Ministro Luiz Fux, de 05/04/2016; Are909527 AgR/RS, de relatoria do Ministro Luiz Fux, de 10/05/2016, e ARE 9264699 AgR/DF, de relatoria do Ministro Roberto Barroso, em 07/06/2016. 
visando a promover ou garantir o direito à saúde. No entanto, há uma evidente falta de preparo técnico dos magistrados quando o assunto é saúde, a fim de avaliar a real necessidade do cidadão, e muitas vezes o magistrado dispõe apenas dos recursos disponibilizados pela própria parte interessada, para embasar sua decisão.

Sobre isso, disserta Cappelletti (1999) que os direitos fundamentais devem ser sempre levados em conta pelos administradores e legisladores e, se isso não ocorrer, cabe a intervenção dos juízes a fim de evitar o extermínio desses direitos, ainda que contrariem cálculos e ações já realizados, e ainda os juízes corram o risco de, agindo assim, assumir uma posição contramajoritária. A criatividade judicial, todavia, não pode ser ilimitada nem arbitrária. Este autor exemplifica que mesmo o direito natural e a tradição podem ajudar o juiz a embasar sua convicção pessoal, tornando a fundamentação de sua sentença mais conectada com os anseios sociais, porém sempre no sentido de promover não a um anseio qualquer, mas a preservação de direitos fundamentais.

Verdadeiramente, o Judiciário, agindo na defesa dos direitos fundamentais e garantindo a prestação do direito à saúde não age invadindo a seara do Legislador, mas sim, age apenas fazendo com que se cumpra aquilo que já está previsto, seja constitucional ou infraconstitucionalmente. $\mathrm{O}$ juiz, na verdade, não cria novas leis, apenas as interpreta, e esta interpretação ,que muitas vezes pode sim ter aspectos subjetivos, deve ser base para a motivação dos atos judiciais, motivação esta prevista em lei e necessária à validade de seu ato.

No que toca à motivação dos atos judiciais, sabe-se que o Judiciário deve buscar, antes de mais nada, a pacificação social, como destaca Hartmann (2014). Portanto, segundo esta autora, pode-se esperar que o Judiciário atue ponderando interesses no caso concreto, e exigindo a implementação de políticas onde elas forem insuficientes ou ausentes. Desta forma, o protagonismo do Judiciário serviria para trazer ao indivíduo o acesso aos direitos fundamentais, para o desenvolvimento de uma vida digna, e que estes direitos fundamentais seriam normas-princípios a serem aplicadas pelo princípio da ponderação. Frisa que não há que se falar em ofensa à separação de poderes, posto que o Judiciário atuaria subsidiariamente aos demais poderes, buscando a justiça social e a adaptação do texto constitucional às realidades presentes no caso concreto.

Aos que contestam esta atuação do Judiciário como sendo invasivo à competência dos demais poderes, Canut e Cadermatori (2011) destacam o "caráter falacioso" destes argumentos porquanto busque o Judiciário a compelir a Administração a cumprir as implementações de direitos sociais por meio de políticas adequadas visto que, segundo estes autores, a legitimidade desta ação decorre não do princípio da soberania popular, mas do próprio Estado de Direito, que possui em seu âmago a essência da garantia da concretização dos direitos fundamentais.

Valle (2013), contudo, apresenta opinião divergente deste entendimento. Chama a aplicação das decisões judiciais de "escolhas trágicas" que o Administrador muitas vezes tem que fazer para dar concretude a essas decisões, uma vez que, segundo a autora, estas sentenças judiciais, favoráveis às demandas individuais, seriam 
prolatadas sem a plena compreensão do seu alcance enquanto política pública, o que geraria "retrocesso social". A autora explicita a visão dual a este processo, trazendo a questão da "bondade" feita ao autor da ação, que se tornaria na verdade uma "maldade" com relação ao coletivo, visto formalmente como terceiro não envolvido e sem interesse no processo, mas que na verdade seria seu destinatário natural da política pelo critério objetivo-formal. Diz que esta procura do indivíduo pelos seus interesses no Judiciário tem raiz no desinteresse pelo processo político e o paternalismo crônico, presentes na história social do país, e que tem levado a um afastamento natural do exercício da cidadania. Isso, segundo a autora, inseriria os atores sociais passivamente na relação judicial individualizada, como destinatários de bens aos quais não possuiriam "sensação de pertencimento", e que colocaria em segundo plano a questão "estrutural, relativa ao cumprimento, pelo poder público, dos compromissos constitucionais".

Apesar do que foi discutido pela autora em tela, vale o comentário de que, se passarmos pelo entendimento assinalado anteriormente não só pelo Ministro Gilmar Mendes, como também pelos demais autores aqui referidos, concluiremos que não se trata de apontar para uma invasão do espaço delimitado pela repartição de poderes ao se conceder a tutela do direito individual do direito à saúde, e sim de exigir o cumprimento do que já está previsto em lei ou, no máximo, de se sopesarem as atuações discricionárias do Administrador, se sentidas pelo Juiz como desproporcionais, em desfavor do cidadão.

Saindo da discussão teórica e trazendo a discussão para o concreto, Boing et al (2013), por meio da análise dos dados acerca da judicialização da assistência farmacêutica no Estado de Santa Catarina, evidenciam que há uma crescente demanda judicial por medicamentos, e que esta é uma tendência nacional. Segundo estas autoras, o valor gasto pela União em 2003 no cumprimento de ordens judiciais que determinavam a dispensação de medicações foi de 180 mil reais e que, em 2007, e isso apenas até o mês outubro, o montante já chegava a 26 milhões de reais, empenhados no mesmo fim. Estas autoras apontam vários fatores para explicar este crescente número de demandas judiciais, tais como a maior informação e organização das pessoas, o envelhecimento populacional, aumentando a onerosidade dos tratamentos, e a "industrialização" da judicialização da saúde por escritórios de advogados especializados na área. Assim sendo, podemos concluir que, longe de ser a questão da judicialização da saúde um tema esgotado, continua a questão a estar presente na rotina dos gestores públicos e do Poder Judiciário.

À parte disso, não podemos desconsiderar eventuais abusos dos autores das demandas. Isso evidentemente pode ocorrer em qualquer lide. Exatamente por causa disso, e para tentar eliminar os conflitos e ansiedades gerados em todas as partes é que entendemos viável a criação de um espaço permanente de discussão institucional, para flexibilização das políticas e dos entendimentos legislativos, visando a atingir o interesse público.

O fato é que o desafio de gestão é tão grande, que o Conselho Nacional de Justiça instituiu um fórum de 
monitoramento e solução das questões relativas à saúde, preconizando uma maior articulação entre os Poderes, a fim de tornar a gestão da área mais eficiente.

\section{ANÁLISE E REFLEXÃO}

Podemos constatar que a jurisprudência está pacificada no que diz respeito à responsabilização solidária dos entes federativos na promoção do direito à saúde, bem como no entendimento deste direito como fundamental, mas a discussão doutrinária sobre a judicialização da saúde parece distante de acabar.

Ao que parece, uma significativa parte dos nossos doutrinadores ainda não se convenceu do entendimento de que a responsabilidade dos entes federativos sobre a prestação a saúde é solidária, e acusam o Judiciário (que alega, com alguma razão, de apenas estar dando cumprimento à lei) de invadir a seara do Executivo, atingindo sua discricionariedade, bem como a do Legislativo, ao usar recursos hermenêuticos pelos quais os juízes dariam interpretação "criativa" às leis, a fim de conceder a tutela do direito à saúde, como se este fosse um direito subjetivo, líquido e certo, e não dependente de recursos orçamentários e definições por meio de políticas públicas.

Embora os votos dos ministros do STF sejam suficientemente motivados e coerentes, ${ }^{12}$ e na medida em que os operadores do Direito continuam encaminhando ao Judiciário conflitos que o próprio STF já considerou como de repercussão geral, percebe-se que essa situação causa ainda um certo descontentamento no âmbito da Administração. Aliás, o que se percebe é que, apesar da repercussão geral, os fatos de as decisões do STF sobre saúde serem de natureza interlocutória e não definitiva causa certa insegurança para o Administrador, já que o Judiciário tem recebido cada vez mais ações visando à proteção da saúde como direito individual.

A insuficiência legislativa (não no sentido da inação, mas da ação excessivamente lenta para as necessidades sociais, que demandam por rapidez cada vez maior na tomada de decisões) não vem ao encontro do que o Poder Constituinte originário pretendeu. Observa-se que se gerou, ao interpretar a Constituição, um viés extremamente complexo de se lidar no dia a dia, que se constituem nas normas de caráter principiológico, de baixa densidade semântica. Podemos detectar estas normas por todo o artigo $5^{\circ}$, e também no artigo $6^{\circ}$ da Constituição. Porém, o Judiciário tem entendido o direito à saúde na forma de direitos subjetivos, com eficácia imediata. Por causa deste entendimento jurisdicional dominante, a Lei n. 8.080/90, que regulamenta as disposições constitucionais citadas, transformou-se numa lei excessivamente técnica e, ao mesmo tempo, genérica, posto que traz atribuições pouco delimitadas à União, adicionando competências mais concretas ao Estados, municípios e Distrito Federal.

\footnotetext{
${ }^{12}$ Sobre a pragmática do discurso de cada ministro do STF no que respeita a sua compreensão do direito constitucional à saúde, cf. Lima (2016).
} 
Vale destacar que a Constituição estabelece, em seu artigo 23, as competências concorrentes dos entes federativos, mas sem definir, de maneira clara, onde começa uma e termina outra, estabelecendo tão somente que é competência comum da União, dos Estados, do Distrito Federal e dos Municípios: "II - cuidar da saúde e assistência pública", e especificando, em seu parágrafo único, que leis complementares devem dispor sobre sua regulamentação. Interessante notar que a redação dada pela Emenda Constitucional n. 53/2006 a este parágrafo trouxe para o plural o termo "lei complementar", grafada pelo legislador originário, talvez pela evidente dificuldade de se fazer uma única lei complementar para atividades tão diversas quanto as dispostas neste artigo.

No que toca aos Legisladores como representantes legítimos do povo, seria talvez de se esperar mais presença em suas bases e mais amplitude de debates em temas nevrálgicos como o da saúde, até para se ter uma efetividade maior quando da elaboração das leis e consequente aplicação quando de sua vigência. Em face disso, talvez até por atuar junto aos interesses dos cidadãos por causa do julgamento de casos concretos, o Judiciário tenha ampliado seu espaço no cenário sócio-político, apresentando uma postura "ativista” e menos conservadora, no que toca pelo menos ao excessivo apego à estrutura legal positivada.

Os recursos hermenêuticos utilizados privilegiam o entendimento do direito social como fundamental, o que nos leva a entender que a positivação do direito à saúde, nos termos da Lei n. 8.080/1990, não se mostrou suficiente para convencer os magistrados quanto a uma repartição absoluta de competências dos entes federativos na prestação da assistência à saúde, prevalecendo a posição de que a responsabilidade de todas as esferas é solidária em todos os aspectos, e não apenas naqueles dispostos na lei.

É dizer que o Judiciário se afasta de um modelo passivo-interpretativo de leis, e se coloca como um ator importante na implementação de um modelo de agir fundamentado, juridicamente seguro, mas proativo, no que diz respeito à garantia dos direitos e liberdades democráticas.

O aumento progressivo das demandas judiciais clamando por concessão de atenção à saúde traduz também mais um movimento social: aquele em que o Judiciário deixa de ser um órgão inacessível à grande maioria da população e se torna a via expressa de acesso do cidadão ao Poder Público. A credibilidade outorgada ao Judiciário como o "protetor" das garantias fundamentais traz sem dúvida um novo momento político, em que muitos paradigmas precisam ser repensados, especialmente no que tange à questão da limitação do direito à saúde.

Se isso por um lado é positivo, por outro é perigoso: sobrecarrega o Judiciário com uma responsabilidade que está longe de ser só sua. Por isso, cremos que seja necessária a construção de um novo espaço de diálogo entre os diversos Poderes e seus diferentes níveis, a fim de se conseguir equacionar o dilema da necessidade versus possibilidade técnica.

Os espaços em tela, no nosso entendimento, poderiam ser mediados por pessoas de notório saber 
técnico e jurídico, desvinculadas das questões discutidas, que atuariam como mediadores dos Poderes envolvidos, a fim de se conduzir o diálogo a um bom termo. Vale lembrar que a técnica da mediação está sendo bem vista por boa parte do Legislativo e do Judiciário e que acaba de ser guindada ao patamar de procedimento obrigatório nos procedimentos judiciais comuns, conforme a Lei n. 13105 /2015. Desta forma, os direitos fundamentais poderiam ser supridos não por uma ponderação abstrata, mas por uma gama concreta de possibilidades articuladas, a fim de não só suprir o direito fundamental individual, mas também de contemplar o direito à saúde em sua dimensão de direito fundamental social.

\section{CONCLUSÃO}

De todo o exposto, entendemos que se deveria trazer o Judiciário à participação direta das decisões administrativas, bem como das elaborações legislativas, num diálogo institucional que permitiria a releitura do princípio da repartição dos poderes. Não se trata aqui de propor uma reforma constitucional, e sim de implementar uma nova lógica de pensar e agir, a fim de alcançar a finalidade principal de todas essas ações, que éo interesse público.

O que se propõe, portanto, é uma releitura do princípio da repartição dos poderes, pugnando-se pela aproximação dos Poderes Políticos no sentido de atuação harmônica e interdependente no exercício de suas funções. A distância entre eles e a forma como cada qual atua, sem se comunicarem institucionalmente uns com os outros, ouvindo-se mutuamente apenas após uma ou outra decisão em casos concretos, tem impedido que o Estado atue com eficiência na prestação de serviços e na promoção de direitos fundamentais, como é o caso da promoção da saúde pela Administração, que a todo momento precisa alterar sua programação por força de ordens judiciais dos mais variados conteúdos, em regra considerando que o direito à saúde é líquido, certo, exigivel nos termos pretendidos pelo cidadão e não segundo os recursos escassos do próprio Estado, disponíveis para atendimento global de toda a sociedade e não apenas para um ou outro autor de demandas judiciais.

O Judiciário não tem acesso a todas as questões analisadas e implementadas pelo Administrador. O juiz se preocupa exclusivamente com o caso concreto posto à sua frente, em geral tratando da necessidade de proteção a um direito que deve ocorrer em tutela de urgência sob risco de perecimento não só do direito, mas do próprio autor. Como se o direito à saúde garantisse a vida do cidadão em toda e qualquer circunstância, e não apenas o direito de acesso a um sistema de tratamento que, infelizmente, é falível e que não foi estruturado para prover o atendimento individualizado que, nos termos maioria das ações judiciais, é em regra exigido do EstadoAdministrador pelo Estado-Juiz.

Propõe-se o diálogo para que tanto o Legislador e o Administrador quanto o Juiz compreendam a extensão e os limites de políticas públicas de saúde e o quanto representa o orçamento da saúde, limite máximo da 
possibilidade de promoção desse direito, a ser repartido de modo coletivo e não de modo individualizado, através da criação de pautas a serem deliberadas pelos três poderes em conjunto, para que o Administrador, de antemão, compreenda quais as demandas individuais que devam ser tratadas, de modo a organizar os recursos de modo eficiente e otimizado para a promoção coletiva da saúde.

Não se busca, com esses diálogos, a restrição do direito fundamental social à saúde ou a evitar que ele seja apreciado pelo Poder Judiciário, mas que este tenha, assim como a própria sociedade, de antemão, diretrizes seguras sobre o que esperar e o que se exigir do Administrador em sua atribuição constitucional de prover saúde a todos os cidadãos.

Decisões discricionárias, que são prerrogativas do Executivo (que decide, assim, como e quando executar determinada ação), prosseguirão sendo tomadas. Porém, no que concerne às ações em saúde, deveriam ser vistas sob outro prisma, em que se incluiriam, na construção dos orçamentos, a necessidade real da população, atualizada na mesma velocidade com que a CONITEC as realiza (e que por sua vez, deveria ter também mais agilidade). Isso demandaria um novo processo de diálogo entre os órgãos públicos, e isso, evidentemente, não é coisa simples de fazer.

Pelo menos no que toca aos últimos dez anos de decisões monocráticas e colegiadas da nossa Suprema Corte a respeito do direito fundamental à saúde, a tendência é de se aceitar esse direito social como garantia fundamental, de responsabilidade solidária (no sentido de sua prestação social) de todos os Entes federativos, e de prestação imediata por qualquer desses entes, seja União, Estado, Distrito Federal ou Município, para atendimento ao cidadão demandante.

Para o bem da prestação eficiente da saúde pelo Administrador, contudo, seria muito importante que tal tendência não se confirmasse. O ideal é que esse diálogo fosse proposto antes de qualquer decisão de mérito do STF sobre as ações judiciais envolvendo direito à saúde, de tal modo que pudesse ter natureza vinculante para todos os poderes do Estado e órgãos do governo, permitindo-se, com isso, que o Estado-Administrador pudesse se desincumbir, com toda segurança para si e para os cidadãos, de sua atribuição de promover e garantir o direito socialà saúde.

Também podemos depreender que a discricionariedade política só se aplica na execução, não na elaboração das normas, e que a questão da judicialização, na realidade não se prende à falta de verbas, e sim à falta de ações políticas e até de um certo desconhecimento do modo de proceder do Poder Público como um todo, visto tanto na relação com a sociedade com o dentro de sua própria estrutura.

Cremos que esta discussão ainda se prolongará por muitos anos, mas esperamos que a pacificação desta controvérsia seja possível por meio do diálogo institucional entre todos os envolvidos. 
THE PROBLEM OF HEALTH JUDICIALIZATION IN BRASIL: SUGGESTING A NEW PATH

\begin{abstract}
The main issue developed in this paper refers to the quantity of judicial interventions in the discretionary action of the Administrators responsible for running health public policies, as well as the legitimacy of such interventions. We aim to contribute to the discussion on the judicial activism on the right to health in Brazil. We have reviewed Brazilian's Supreme Court (STF) precedents on this theme, current legislation and corresponding literature. It was confirmed that, although STF considers that the promotion of the right to health is severally attributable to cities, states and Federal governments, enforcing to all and any of them the duty to provide health to general public, it seems it does not acknowledge that such consideration causes serious problems in Government budget. Besides, maybe for some inertia of Legislative branch, but certainly due to Judicial activism, there are uncountable number of law suits pleading individual guarantees to health. Researchers discuss on the outcome of this clash of Government branches, seeking for alternatives for budgeting the right to health. We defend a review on the matter of judicial activism and suggest the creation of institutional dialogues so as Government to establish, by its three branches, how it should act on the provision of the right to health.
\end{abstract}

Keywords: Health judicialization. Judicial activism. Right to health. Public policies. Institutional dialogues.

\title{
REFERENCIAS
}

BOING, Alexandra; BLOEMER, Neusa Sens; ROESLER, Claudia, e FERNANDES, Simone. A judicialização do acesso aos medicamentos em Santa Catarina: um desafio para a gestão do sistema de saúde. Revista de Direito Sanitário, São Paulo, v.14. n.1, p 82-97, mar/jun 2013. Disponível em http://www.revistas.usp.br/rdisan/article/view/56625/59642. Acesso em 10/04/2016.

BRASIL. Presidência da República. Constituição Federal. Brasília, 1988. Disponível em <http://www.planalto.gov.br/ccivil_03/constituicao/constituicao.htm>, acesso em 10/04/2016.

Presidência da República. Lei no 8080, de 19 de setembro de 1990. Brasília, 1990. Dispõe sobre as condições para a promoção, proteção e recuperação da saúde, a organização e o funcionamento dos serviços correspondentes e dá outras providências. Disponível em http://www.planalto.gov.br/ccivil_03/leis/18080.htm, acesso em 10/04/2016.

Presidência da República. Lei no 12.401, de 28 de abril de 2011. Brasília, 2011. Altera a Lei no 8.080, de 19 de setembro de 1990, para dispor sobre a assistência terapêutica e a incorporação de tecnologia em saúde no âmbito do Sistema Único de Saúde - SUS. Disponível em http://www.planalto.gov.br/ccivil_03/_Ato20112014/2011/Lei/L12401.htm. Acesso em 21/07/2016.

Presidência da República. Decreto no 7646, de 21 de dezembro de 2011. Dispõe sobre a Comissão Nacional de Incorporação de Tecnologias no Sistema Único de Saúde e sobre o processo administrativo para incorporação, exclusão e alteração de tecnologias em saúde pelo Sistema Único de Saúde -SUS, e dá outras providências.Disponível em: http://www.planalto.gov.br/ccivil_03/_Ato20112014/2011/Decreto/D7646.htm. Acesso em 9/04/2016.

Presidência da República. Lei Complementar no 141, de 13 de janeiro de 2012. Brasília,2012. Regulamenta o $\$ 3^{\circ}$ do art. 198 da Constituição Federal para dispor sobre os valores mínimos a serem aplicados anualmente pela União, Estados, Distrito Federal e Municípios em ações e serviços públicos de saúde; estabelece os critérios de rateio dos recursos de transferências para a saúde e as normas de fiscalização, avaliação e controle 
das despesas com saúde nas 3 (três) esferas de governo; revoga dispositivos das Leis nos 8.080 , de 19 de setembro de 1990, e 8.689, de 27 de julho de 1993; e dá outras providências. Disponível em <http://www.planalto.gov.br/ccivil_03/leis/LCP/Lcp141.htm> Acesso em 21/07/2016.

Supremo Tribunal Federal. Recurso Extraordinário 271286/RS. Recorrente: Município de Porto Alegre e Estado do Rio Grande do Sul. Recorrido: Diná Rosa Vieira. j. 02/08/2000. Relator Ministro Celso de Mello, em 02/08/2000. Disponível em http://www.stf.jus.br/portal/jurisprudencia/listarJurisprudencia.asp?s1=\%28\%28271286\%29\%29+NAO+S\%2E PRES\%2E\&base=baseMonocraticas. Acesso em 21/07/2016.

Supremo Tribunal Federal. Audiência Pública sobre a judicialização da saúde. 27 a 29 de abril e 04 a 07de maio de 2009. Brasília. Notas taquigráficas do dia 27 de abril de 2009. Sessão de abertura. Ministro Gilmar Mendes.

Disponível

em http://www.stf.jus.br/arquivo/cms/processoAudienciaPublicaSaude/anexo/Abertura_da_Audiencia_Publica _MGM.pdf.Acesso em 21/07/2016.

Supremo Tribunal Federal. Agravo Regimental da Suspensão de Liminar 47/PE. Agravante: Estado de Pernambuco. Agravados: União, Ministério Público Federal, Ministério Público do Estado de Pernambuco e Município de Petrolina. Relator Ministro Gilmar Mendes, j. 17/03/2010. Disponível em http://redir.stf.jus.br/paginadorpub/paginador.jsp?docTP=AC\&docID=610254. Acesso em 21/07/2016.

Supremo Tribunal Federal. Agravo Regimental na Suspensão de Tutela Antecipada 175/CE. Agravante: União. Agravados: Ministério Público Federal, Clarice Abreu de Castro Neves, Município de Fortaleza e Estado do Ceará. Relator Ministro Gilmar Mendes, j. 17/03/2010. Disponível em http://www.stf.jus.br/portal/jurisprudencia/listarJurisprudencia.asp?s1=\%28STA+175+2010\%29\&base=baseA cordaos. Acesso em 21/07/2016.

Supremo Tribunal Federal. Suspensão de Segurança SS3989/PI. Requerente: Estado do Piauí. Requerido: Tribunal de Justiça do Estado do Piauí. Relator Ministro Gilmar Mendes. j. 07/04/2010. Disponível em

http://www.stf.jus.br/portal/jurisprudencia/listarJurisprudencia.asp?s1=\%28\%28SS+3989+2010\%29\%29+E+S \%2EPRES\%2E\&base=basePresidencia Acesso em 21/07/2016.

Supremo Tribunal Federal. Notícias. Poder Público deve custear medicamentos e tratamento de alto custo a portadores de doenças graves, decide o Plenário do STF. Brasília, 17 de março de 2010. Disponível em http://www.stf.jus.br/portal/cms/verNoticiaDetalhe.asp?idConteudo=122125\&caixaBusca=N . Acesso em 11/04/2016.

Supremo Tribunal Federal. Agravo Regimental no Recurso Extraordinário 717290-RS. Agravante: União. Agravado: Álvaro Luiz Silveira Saideles. Relator: Ministro Luiz Fux, j. 18/03/2014. Disponível em http://redir.stf.jus.br/paginadorpub/paginador.jsp?docTP=TP\&docID=5595657. Acesso em 21/07/2016.

Supremo Tribunal Federal. Recurso Extraordinário780683/PE Recorrente: União. Recorrido: Arlindo Barbosa dos Santos. Relator Ministro Teori Zavascki. j. 01/08/2014. Disponível em http:/ / www.stf.jus.br/portal/jurisprudencia/listarJurisprudencia.asp?s1=\%28\%28RE+780683+2014\%29\%29+N $\mathrm{AO}+\mathrm{S} \% 2 \mathrm{EPRES} \% 2 \mathrm{E} \&$ base=baseMonocraticas. Acesso em 21/07/2016.

Supremo Tribunal Federal. Agravo Regimental no Recurso Extraordinário com agravo 801676- PE. Agravante: Estado de Pernambuco. Agravado: Patrícia Moraes Dantas de Souza. Relator Ministro Luiz Roberto Barroso, j. 19/08/2014. Disponível em http://redir.stf.jus.br/paginadorpub/paginador.jsp?docTP=TP\&docID=6639025. Acesso em 21/07/2016.

Supremo Tribunal Federal. Agravo regimental no recurso extraordinário. Agravante: União Agravado: Vicente da costa Camarão. Relatora Ministra Rosa Weber. j. 16/02/2016. Disponível em http://www.stf.jus.br/portal/jurisprudencia/listarJurisprudencia.asp?s1=\%28RE+933857\%29\&base=baseAcord aos Acesso em 21/07/2016.

Supremo Tribunal Federal. Agravo regimental no recurso extraordinário com agravo. Agravante: Município de Cariacica. Agravado: José Luiz Helmer. Relator Ministro Edson Fachim. j. 15/03/2016. Disponível 
em

http: //www.stf.jus.br/portal/jurisprudencia/listarJurisprudencia.asp?s 1=\%28ARE+936301\%29\&base=baseAcor daos. Acesso em 21/07/2016.

Supremo Tribunal Federal. Agravo regimental no recurso extraordinário com agravo. Agravante: Estado de Roraima. Agravado: Alair Bonfim de Barros. Relator Ministro Luiz Fux. j. 05/04/2016. Disponível em http: //www.stf.jus.br/portal/jurisprudencia/listarJurisprudencia.asp?s1=\%28ARE+831915\%29\&base=baseAcor daos Acesso em 21/07/2016.

Supremo Tribunal Federal. Agravo regimental no recurso extraordinário com agravo. Agravante: União. Agravado: Erich Adiers. Relator Ministro Luiz Fux, j. 10/05/2016. Disponível em http: / / www.stf.jus.br/portal/jurisprudencia/listarJurisprudencia.asp?s1=\%28ARE+909527\%29\&base=baseAcor daos Acesso em 21/07/2016.

Supremo Tribunal Federal. Agravo Regimental no Recurso Extraordinário com Agravo. Agravante: Distrito Federal. Agravada: Lizzie Andrea Machado Silva. Relator Ministro Luiz Roberto Barroso, j. 07/06/2016. Disponível http: // www.stf.jus.br/portal/jurisprudencia/listarJurisprudencia.asp?s1=\%28ARE+926469+\%29\&base=baseAc ordaos Acesso em 21/07/216.

CANUT, Letícia, e CADERMATORI, Sergio. Neoconstitucionalismo e direito à saúde: algumas cautelas para a análise da exigibilidade judicial. Revista de Direito Sanitário, São Paulo, v.12, p. 9-40, Mar/jun 2011. Disponível em http://www.revistas.usp.br/rdisan/article/view/13235. Acesso em 11/04/2016.

CAPPELLETTI, Mauro: Juízes Legisladores? 1ª Ed. Tradução de Carlos Alberto Álvaro de Oliveira. Porto Alegre, Sergio Antonio Fabris, 1999, p. 73-107.

DALLARI, Sueli Gandolfi. A construção do direito à saúde no Brasil. Revista de Direito Sanitário. São Paulo, v. 9, n. 3, p. 9-34 Nov 2008 / fev. 2009. Disponível em http://www.revistas.usp.br/rdisan/article/view/13128. Acesso em 10/04/2016.

DANTAS, Gisela Pimenta Gadelha; FERREIRA, Ricardo Rielo; COSTA, Larissa Camargo. O papel do STF na efetividade dos direitos fundamentais à saúde e à educação. In Quaestio Juris, v. 6, n. 1, 2013, p. 63-84. Disponível em http://www.e-publicacoes.uerj.br/index.php/quaestioiuris. Acesso em 11/04/2016.

HARTMANN, Michelle Chalbaud Biscala: Ativismo Judicial e a Concretização de Prestações Sociais. Revista Direitos Fundamentais \& Democracia, 2011, v.9, n.9, p.157-162. Disponível em http://revistaeletronicardfd.unibrasil.com.br/index.php/rdfd/article/viewFile/54/53. Acesso em 10/04/2016.

HUNT, Paul e KHOSLA, Rajat: Acesso a medicamentos como direito humano. Revista Internacional de Direitos Humanos, ano 5, no 8, junho de 2008, p.101-121. Disponível em http://www.conectas.org/pt/acoes/sur/edicao/8/1000322-acesso-a-medicamentos-como-um-direito-humano Acesso em 21/07/2016

LIMA, Fernando Rister de Sousa. Descrição pragmática da atuação do Supremo Tribunal Federal em direito à saúde. Quaestio Juris, v. 9, n. 1, 2016, p. 56-83. Disponível em http://www.epublicacoes.uerj.br/index.php/quaestioiuris. Acesso em 11/04/2016.

SANTOS-PINTO, Cláudia Du Bocage et al. Novos delineamentos da Assistência Farmacêutica frente à regulamentação da Lei Orgânica da Saúde. Cad. Saúde Pública, Rio de Janeiro, v. 29, n. 6, p. 1056-1058, junho 2013. Disponível em http://www.scielosp.org/scielo.php?script=sci_arttext\&pid=S0102- 
$311 X 2013001000002 \& \operatorname{lng}=$ en\&nrm=iso. Acesso em 21/07/2016.

SARLET, Ingo Wolfgang. Curso de Direito Constitucional. São Paulo, RT, 2012.

SILVA, Hudson P; PETRAMALE, Clarice A; ELIAS, Flavia T S. Avanços e desafios da política nacional de gestão de tecnologias em saúde. Rev. Saúde Pública, v. 46, supl. 1, p. 83-90, dezembro de 2012. Disponível em http://www.scielo.br/scielo.php?script=sci_arttext\&pid=S0034-89102012000700012\&lng=en\&nrm=iso. Acesso em 11/04/2016.

VALLE, Vanice Regina Lírio do: Controle judicial de políticas públicas: sobre os riscos da vitória da semântica sobre o normativo. Revista de Direitos Fundamentais e Democracia, v 14, n.14, p 387-408, jul/dez 2013. Disponível em http://revistaeletronicardfd.unibrasil.com.br/index.php/rdfd/article/viewFile/420/348, acesso em 21/07/2016.

Trabalho enviado em 11 de abril de 2016.

Aceito em 25 de agosto de 2016. 